\title{
USEFULNESS OF A NEW PROGNOSTIC INDEX FOR ALCOHOLIC HEPATITIS
}

\author{
Jazon Romilson de Souza ALMEIDA, Roberta Chaves ARAÚJO, Giane Vieira de CASTILHO, \\ Letícia STAHELIN, Lívia dos Reis PANDOLFI and Cecília Queiroz SILVA
}

\begin{abstract}
Background - Alcoholic liver disease is a major cause of end-stage liver disease worldwide and severe forms of alcoholic hepatitis are associated with a high short-term mortality. Objectives - To analyze the importance of age-bilirubin-INR-creatinine (ABIC) score as an index of mortality and predictor for complications in patients with alcoholic hepatitis. To evaluate its correlation with those complications, with risk of death, as well as the scores model for end stage liver disease (MELD) and Maddrey's discriminat function. Methods - A total of 46 medical records of patients who had been hospitalized with alcoholic hepatitis were assessed retrospectively with lab tests on admission and after seven days. Score calculations were carried out and analyzed as well. Results - The scores showed positive reciprocal correlation and were associated with both hepatic encephalopathy and ascites. ABIC index, which was classified as high risk, presented as a risk factor for these complications and for death. In univariate logistic regression analysis of mortality, the ABIC index at hospital admission odds ratio was 19.27, whereas after 7 days, it was 41.29 . The average survival of patients with ABIC of low and intermediate risk was 61.1 days, and for those with high risk, 26.2 days. Conclusion-ABIC index is a predictor factor for complications such as ascites and hepatic encephalopathy, as well as for risk of death. Thus, it is a useful tool for clinical practice.
\end{abstract}

HEADINGS - Alcoholic hepatitis. Severity of illness index. Bilirrubin. Creatinine. Mortality

\section{INTRODUCTION}

Alcohol abuse represents a situation of expressive morbimortality nowadays, despite the advances of modern medicine and improved access to existing therapies on the part of the population ${ }^{(1,6,8,12,17)}$.

In the western world, alcoholic liver disease (ALD) is among the 10 most common causes of death ${ }^{(12)}$. Around $10 \%$ to $12 \%$ of the world's population is addicted to alcohol ${ }^{(17)}$ and $11.2 \%$ of Brazilians who live in the 107 biggest cities have this problem ${ }^{(6)}$. Alcohol abuse is the third leading cause of death in the USA, with mortality rate disproportionately higher among young people. Hence, 30 years of life are lost through related death ${ }^{(13)}$.

It is estimated that in the USA, alcohol accounts for 100,000 deaths per year ${ }^{(1)}$, and $20 \%$ of addicts develop fibrosis and subsequent liver cirrhosis and complications such as ascites, spontaneous bacterial peritonitis (SBP), esophageal varices (EV) and the possibility of upper gastrointestinal bleeding (UGB), hepatic encephalopathy (HE) and hepatocellular carcinoma (HCC), making liver transplantation the only definitive treatment and cure $^{(2,8)}$.

Alcoholic hepatitis (AH) is, within the scope of ALD, an acute inflammatory disease that occurs in patients with alcohol-related chronic liver disease. In its severe form, it leads to death within 30 days in $50 \%{ }^{(14,16)}$ of the cases. Thus, recognizing this issue is of ultimate importance when it comes to manage these patients.

Various prognostic indexes have been developed and used to indicate not only the severity of $\mathrm{AH}$ but also the survival of patients diagnosed with this disease. The discriminant function index was first described by Maddrey and collaborators in 1978. This score was then modified (modified discriminant finction or $\mathrm{mDF}$ ) using prolongation of prothrombin time (PT) in seconds instead of absolute value of $\mathrm{PT}^{(3)}$. Its cutoff point is 32 , which indicates patients with severe $\mathrm{AH}$ and high mortality rate in the short run. The American College of Gastroenterology recommends that $\mathrm{AH}$ patients with Maddrey function higher than 32 should undergo corticosteroid thera$\mathrm{py}^{(4)}$. Even though this score is easy to calculate and has been validated in several studies, it makes use of PT, which may vary among laboratories, depending on the type of thromboplastin used, which might be a limitation ${ }^{(4,18)}$

Model for end stage liver disease (MELD) score was initially developed to predict survival of patients with cirrhosis undergoing transjugular intrahepatic

Declared conflict of interest of all authors: none

Disclosure of funding: no funding received

Departamento de Clínica - Gastroenterologia - Faculdade de Ciências Médicas, Universidade de Campinas, Campinas, SP, Brazil.

Correspondence: Dra. Roberta Chaves Araújo. Rua Clodoaldo de Oliveira, 52. Centro. CEP: 35600-000. Bom Despacho, MG, Brasil. E-mail: robertaca1907@gmail.com 
portosystemic shunting ${ }^{(11)}$. It has since been revised and validated to predict survival for patients with cirrhosis and is the basis for organ donor allocation in liver transplantation ${ }^{(11)}$. It is useful for predicting 3 month mortality of patients with severe AH not treated with corticosterois ${ }^{(4)}$. However, the cutoff point to recognize severe $\mathrm{AH}$ is controversial, with several studies showing different values ${ }^{(19)}$.

Age-bilirubin-INR-creatinine (ABIC) index, developed in 2008 , is able to identify not only good prognosis in $\mathrm{AH}$ patients who will benefit from clinical support (nutritional and psychological), but also those high risk patients who might be candidates to new therapies and intensive care. This score predicts the response to corticosteroid therapy and on top of that, the mortality within 90 days and 1 year $^{(5)}$. As it has been developed recently, more studies about the evidence of its benefits are necessary.

Considering the need to identify and treat adequately severe forms of $\mathrm{AH}$, we are going to assess the usefulness of ABIC as a prognostic index of mortality and predictor of complications. Correlate it with the Maddrey and Meld indexes, and with the survival at 90 days in $\mathrm{AH}$ patients.

\section{METHODS}

\section{Patients}

This is an observational and retrospective study carried out through the revision of the medical records of patients diagnosed with $\mathrm{AH}$, who were assisted by the physicians of the Clinics Hospital $(\mathrm{CH})$ between January 2004 and March 2012. The study was approved by the local Ethics Committee.

The following inclusion criteria were considered: age $>18$, patients diagnosed with AH by clinical, laboratory or histological parameters ${ }^{(4,7,9)}$. The exclusion criteria were as follows: patients with malignant neoplasms, diagnosed with acute pancreatitis, obstruction of extrahepatic bile ducts, as well as those who were not assisted by the gastroenterology team.

The criteria for $\mathrm{AH}$ diagnosis were: clinical history of chronic alcoholism with $>50 \mathrm{~g} /$ day alcohol intake on average, information about alcohol abuse in the previous days and weeks, clinical signs such as fatigue, anorexia, abdominal discomfort, signs of hepatic decompensation, painful hepatomegaly or fever and altered lab tests (elevated aminotransferase levels, gamma-glutamyl transpeptidase (GGT) levels, leukocytosis with predominance of polymorphonuclear cells or increase in the mean corpuscular volume $(\mathrm{MCV})^{(4)}$.

\section{Data collection}

The following laboratory tests were analyzed: aspartate aminotransferase (AST), alanine aminotransferase (ALT), total bilirubin levels (BIL), alkaline phosphatase (ALP), GGT, serum albumin (A), leucocytes, platelet count, PT expressed in international normalized ratio (INR), MCV, creatinine, urea, serum sodium and serum potassium.

The prognostic factors used to classify the severity of $\mathrm{AH}$ were: Maddrey, with the formula [4.6 $\times(\mathrm{PT}$ test - control $)]$ + serum bilirubin $(\mathrm{mg} / \mathrm{dL})^{(3)}$, MELD $(3.78 \times$ loge [serum bilirubin $(\mathrm{mg} / \mathrm{dL})]+11.2 \times$ loge $[\mathrm{INR}]+9.57 \times$ loge [serum creatinine $(\mathrm{mg} / \mathrm{dL})]+6.43)^{(11)}$ and ABIC index. It is calculated using the following formula: (age in years $\mathrm{x} 0.1)+($ bilirubin $+\mathrm{mg} / \mathrm{dL} \times 0.08)+($ creatinine $\mathrm{mg} / \mathrm{dL} \times 0.3)+(\mathrm{INR} \times 0.8)^{(5)}$, according to the patient laboratory data on admission to hospital and seven days later ${ }^{(18)}$. All tests were carried out within the routine of the Clinical Gastroenterology Service, Department of Internal Medicine and were sent to the $\mathrm{CH}$ Central Laboratory. The treatment performed in patients was corticotherapy, use of pentoxifylline or clinical support in those cases that specific drugs were not indicated.

\section{Statistical analysis}

The evaluation of complications of $\mathrm{AH}$ patients was conducted by analyzing the frequency of categorical variables. For continuous variables, a descriptive statistical analysis was used including average, median and standard deviation, as well as minimum and maximum values. Bivariate analysis and univariate logistical regression analysis were performed to evaluate the relationship among prognostic indexes associated with complications and death.

The correlation among prognostic indexes was obtained by the Spearman's correlation coefficient. The Kaplan-Meier method was adopted so as to analyze survival in hospitalized AH patients. The log-rank test was used to compare survival curves. A significance level of 5\% was adopted for these statistical tests $(P<0.05)$.

All the collected data were checked and included in a database from the Excel programmer (2010), with further analysis using the Statistical Package for Social Science (SPSS) for Windows, version 17.0.

\section{RESULTS}

Between January, 2004 and March, 2012, 74 AH patient records from the Hospital were identified. Twenty-eight patients were excluded, 23 of whom for having been admitted by other clinics rather than the gastroenterology team; 2 of them without a diagnostic confirmation for $\mathrm{AH} ; 1$ with lymphoma; 1 with cirrhosis caused by sclerosing cholangitis; and one whose record was not found. Forty six records were analyzed.

\section{Patient clinical data}

Most patients were male ( $89 \%$ ), with male/female ratio of $8: 1$. The average age was 43 , being 27 the minimum age and 75 the maximum age.

Laboratory data were collected at admission, at 7 days, and were used to calculate ABIC index, Maddrey and MELD, as well as in a comparative analysis of these scores between the admission date and 7 days later (Table 1).

Among the complications presented by $\mathrm{AH}$ patients, ascites, $\mathrm{HE}$ and $\mathrm{EV}$ showed representative frequency, $71 \%$, $45.7 \%$ and $34 \%$, respectively. EV was not correlated with studied prognostic indexes. Therapy with corticoid was done in $80 \%$ of the patients and the use of pentoxifylline was done in $47.8 \%$ of all. 
TABLE 1. Comparative analysis of prognostic indexes at admission and at 7 days

\begin{tabular}{|c|c|c|c|c|c|c|}
\hline Characteristic & $n \dagger$ & $\tilde{a}+(+-s d \rrbracket)$ & $\mathrm{m} \S$ & Value Minimum & Maximum & $P$-value* \\
\hline \multicolumn{7}{|l|}{$\mathrm{ABIC}$} \\
\hline at admission & 37 & $8.81(2.47)$ & 8.5 & 4.9 & 16.0 & 0.023 \\
\hline at 7 days & 37 & $8.09(2.40)$ & 7.6 & 4.1 & 17.0 & \\
\hline \multicolumn{7}{|l|}{ Maddrey } \\
\hline at admission & 39 & $87.88(69.71)$ & 64 & 6.6 & 331 & 0.001 \\
\hline at 7 days & 39 & $61.93(42.74)$ & 45 & 11 & 203 & \\
\hline at 7 days & 36 & $24.96(8.58)$ & 23.5 & 6.7 & 43 & \\
\hline
\end{tabular}

ABIC: Age-bilirubin-INR-creatinine; †n: number of patients; $\ddagger$ ã: average; §m: median; sd: standard deviation; $* P<0.05$

Table 2 shows the revised results of univariate logistic regression analysis to study the prognostic indexes related to ascites. In this table, ABIC score is presented in accordance with its classification, which might be low $(<6.71)$, intermediate (6.71-8.99) and high risk (>9.0), depending on its punctuation.

TABLE 2. Univariate logistic progression analysis of ascites

\begin{tabular}{lcccc}
\hline Variable & $\mathrm{n}^{* *}$ & $\boldsymbol{P}$-value* & OR $\dagger$ & CI 95\% OR $\%$ \\
\hline ABIC at 7 days & & & & \\
High risk & 10 & 0.028 & 16.67 & $1.36-204.03$ \\
Maddrey at 7 days & 39 & 0.009 & 1.133 & $1.031-1.244$ \\
MELD at admission & 36 & 0.029 & 1.193 & $1.018-1.398$ \\
MELD at 7 days & 36 & 0.009 & 1.285 & $1.064-1.550$ \\
\hline
\end{tabular}

ABIC: Age-bilirubin-INR-creatinine; $* P<0.05 ; * *$ n: number of patients; $\nmid$ OR: odds ratio; $\ddagger$ CI $95 \% \mathrm{OR}=95 \%$ : confidence interval odds ratio0

Table 3 shows the results for univariate logistic regression analysis to study factors related to HE. The Spearman correlation coefficient was used to measure the correlation among prognostic indexes (nonparametric). ABIC prognostic indexes, Maddrey and MELD presented a positive correlation. The correlation coefficient $(\mathrm{r})$ between admission $\mathrm{ABIC}$ and Maddrey was 0.48 . Between admission MELD and ABIC was 0.66 (Figure 1). This correlation was kept positive in the analysis between the indexes after 7 days, with $r=0.60$ for ABIC and Maddrey, and $r=0.62$ for MELD and ABIC.

TABLE 3. Univariate logistic regression analysis of hepatic encephalopathy

\begin{tabular}{lllll}
\hline Variable & $\mathrm{n}^{* *}$ & $\boldsymbol{P}$-value & OR $\dagger$ & CI 95\% OR $\neq$ \\
\hline ABIC at 7 days & & & & \\
High risk & 9 & 0.035 & 11.25 & $1.19-106.11$ \\
Maddrey at 7 days & 39 & 0.022 & 1.025 & $1.004-1.047$ \\
MELD at admission & 36 & 0.018 & 1.131 & $1.021-1.252$ \\
MELD at 7 days & 36 & 0.004 & 1.199 & $1.061-1.355$ \\
\hline
\end{tabular}

ABIC: Age-bilirubin-INR-creatinine; $* P<0.05 ; * *$ n: number of patients; $\dagger$ OR: odds ratio; $\ddagger \mathrm{CI} 95 \% \mathrm{OR}=95 \%$ : confidence interval odds ratio

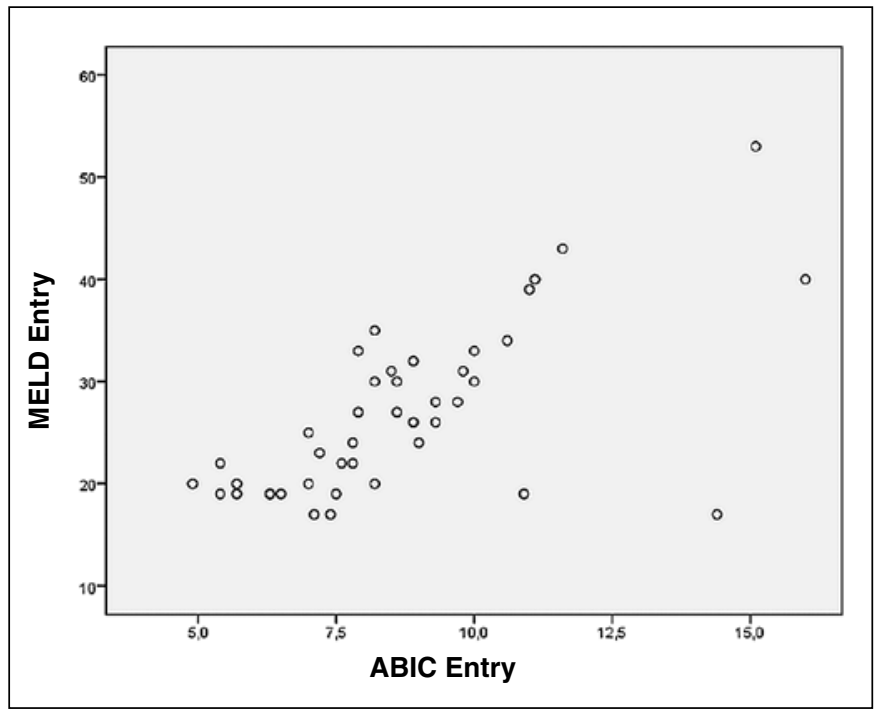

FIGURE 1. Association between Age-bilirubin-INR-creatinine (ABIC) and MELD at admission. Spearman correlation coefficient. n: number of patients; r: correlation coefficient; $P<0.05$

Table 4 describes the relationship between outcome and prognostic indexes. Table 5 shows the results of univariate logistic regression analysis to study facts related to mortality. The Maddrey index on admission was not correlated with death.

TABLE 4. Descriptive analysis of the relationship between outcome and prognostic indexes for alcoholic hepatitis patients

\begin{tabular}{lccc}
\hline Variable & \multicolumn{2}{c}{ Average } & P-value* \\
& Death & No death & \\
\hline \multirow{2}{*}{ ABIC at admission at 7 days } & 9.94 & 8.08 & 0.002 \\
& 9.79 & 7.33 & $<0.001$ \\
Maddrey at admission at 7 days & 102.72 & 76.38 & 0.009 \\
& 98.69 & 44.52 & $<0.001$ \\
MELD at admission at 7 days & 30.69 & 24.93 & 0.008 \\
& 33.45 & 21.32 & $<0.001$ \\
\hline
\end{tabular}

ABIC: Age-bilirubin-INR-creatinine; $* P<0.05$ 
TABLE 5. Univariate logistic regression analysis of factors associated with mortality

\begin{tabular}{|c|c|c|c|c|}
\hline Variable & $\mathrm{n}^{* *}$ & P-value* & $\mathrm{OR} \dagger$ & CI $95 \%$ OR $\ddagger$ \\
\hline $\mathrm{ABIC}$ at admission & 37 & 0.037 & 1.388 & $1.021-1.886$ \\
\hline $\mathrm{ABIC}$ at 7 days & 37 & 0.016 & 1.744 & $1.110-2.741$ \\
\hline $\mathrm{ABIC}$ at admission high risk & 8 & 0.012 & 19.27 & $1.01-393.40$ \\
\hline $\mathrm{ABIC}$ at 7 days high risk & 8 & 0.002 & 41.29 & $1.84-927.49$ \\
\hline Maddrey at 7 days & 39 & 0.003 & 1.040 & $1.014-1.066$ \\
\hline MELD at admission & 36 & 0.048 & 1.094 & $1.01-1.195$ \\
\hline MELD at 7 days & 36 & 0.003 & 1.291 & $1.094-1.524$ \\
\hline
\end{tabular}

ABIC: Age-bilirubin-INR-creatinine; $* * \mathrm{n}$ : number of patients; $* P<0,05 ; \nmid \mathrm{OR}$ : odds ratio; $\ddagger$ CI $95 \% \mathrm{OR}=95 \%$ : confidence interval odds ratio $\mathrm{n}=43$; $\mathrm{r}=0.662 ; P<0.001$

For survival analysis during hospitalization, both low and intermediate risk $\mathrm{ABIC}$ were compared with high risk because there was no death in low risk ABIC scores. There was a significant difference among ABIC classifications, with the lowest survival rate among high-risk ABIC patients (Figure 2).

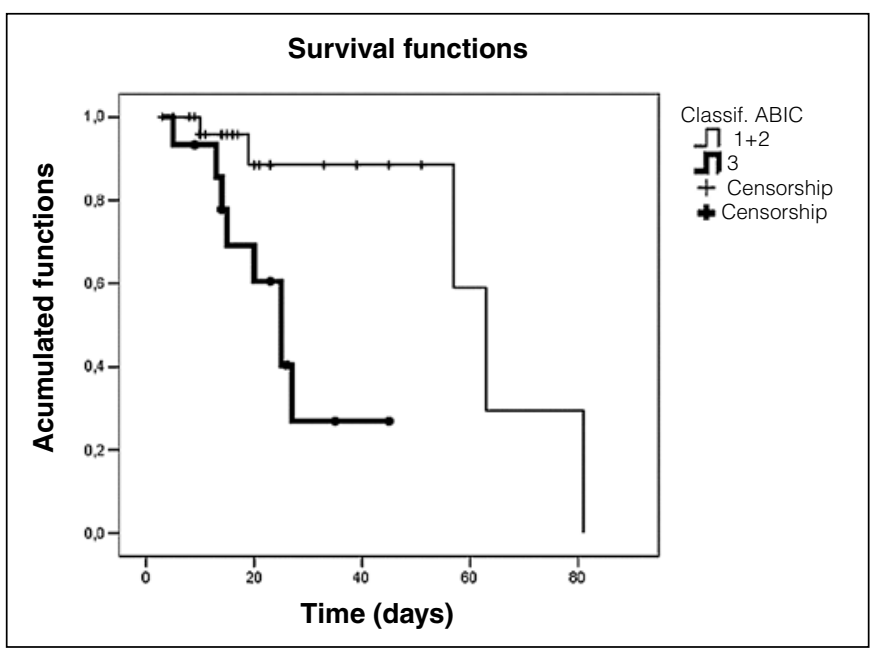

FIGURE 2. Survival analysis among Age-bilirubin-INR-creatinine (ABIC) classes $(P=0.05)$

$1+2=$ low and intermediate risk ABIC. 3 =high-risk ABIC. Censorship: death

\section{DISCUSSION}

In medical practice, several scores are available to assess both the severity of $\mathrm{AH}$ and the survival of patients presenting this disease ${ }^{(20)}$. The ABIC index is a new system of stratification of $\mathrm{AH}$ patient risk of death developed by Dominguez et al. in Barcelona. Using a cut off value is 6.71 and 9.0, patients with low, intermediate and high risk for death from $\mathrm{AH}$ at 90 days and one year can be determined ${ }^{(5)}$.

In a longitudinal analysis of the studied prognostic indexes, we identified that all scores showed a decrease 7 days after admission, which indicates that the clinical support provided was an important improvement in patient clinical signs.

Our study showed that ascites and $\mathrm{HE}$ were complications correlated with prognostic indexes. The high-risk ABIC index 7 days after admission was a risk predictor for those complications, according to a univariate logistic regression analysis. Among the problems presented by AH patients, mainly when there is associated cirrhosis, ascites is generally one of the first complications to appear. In addition, HE is related to the highest mortality ${ }^{(10)}$. In medical practice, the score previously mentioned might help recognize $\mathrm{AH}$ patients who present risk of those complications, and thereby start appropriate therapy. Dominguez et al. found a better response to corticosteroid therapy in patients with intermediate risk of death. However, neither low- nor high-risk ABIC patients benefited from this treatment ${ }^{(5)}$.

We identified a positive correlation among ABIC index and Maddrey and MELD scores at admission and after 7 days as well. Typically, the calculation of Maddrey index predicts the prognostic of $\mathrm{AH}^{(15)}$. Nevertheless, various studies have been comparing the scores. Singal et al. have assessed ABIC, Maddrey and MELD scores, as well as Glasgow alcoholic hepatitis score (GAHS), and have found that ABIC is the best independent predictor of 90-day mortality ${ }^{(19)}$. This index is highly accurate for identifying bad prognosis patients and those who do not respond to corticotherapy ${ }^{(5)}$.

Our study has identified that all patients who died during hospitalization presented high risk ABIC, whereas those who survived had intermediate risk score. All patients classed as low risk survived. Our results are unprecedented, since no reports of the relationship between ABIC score and mortality have been found in the literature.

In a univariate logistic regression analysis, high-risk ABIC score was a risk factor for death with odds ratio at 7 days higher than at admission. Hence, we observed that a reevaluation of the prognostic index after 7 days improves prediction of risk of death.

The average survival of patients with low and intermediate risk ABIC was 61.1 days and for those with high risk, 26.2 days. In accumulated survival analysis, we identified $100 \%$ survival after 7 days, $88.5 \%$ in 30 days and $59 \%$ in 60 days in patients with low and intermediate risk ABIC. The accumulated survival of patients with high risk ABIC was $93.3 \%$ at 7 days and $26.9 \%$ at 30 and 60 days. In the medical literature, the data refer to $90 \%$ survival, being $100 \%$ for low risk $\mathrm{ABIC}, 70 \%$ for intermediate and $25 \%$ for high risk ${ }^{(18)}$. 
The ideal prognostic index should be simple, accurate, reliable, objective and validated by a prospective study both in the country of origin and abroad. Moreover, it should not only guide the beginning of the treatment but also its response. Each score mentioned above has advantages and limitations; thus, it is still necessary to search for a score which provides all the ideal items.

Our study presented limitations such as the number of patients who were assessed and the dependence of the data obtained retrospectively in the records. Thus, a prospective study with more patients is needed to complete the validation of the ABIC score.
In conclusion, since ABIC score shows good accuracy for identifying patients with risk of complications such as ascites and HE, as well as for predicting mortality of those classed as high risk patients, it should be used to manage AH patients.

\section{Author contribution}

Almeida JRS coordinated this study; Araújo RC participated in the survey execution, writing of text, statistical analysis; Castilho GV participated in the survey execution and statistical analysis; Stahelin L, Pandolfi LR and Silva CQ participated in the data collection.

Almeida JRS, Araújo RC, Castilho GV, Stahelin L, Pandolfi LR, Silva CQ. Utilidade de um novo índice prognóstico na hepatite alcoólica. Arq Gastroenterol. 2015,52(1):22-6.

RESUMO - Contexto - A doença hepática alcoólica é uma das maiores causas de doença hepática avançada no mundo, sendo que as formas graves de hepatite alcoólica estão associadas a alta mortalidade a curto prazo. Objetivo-Avaliar a importância do índice age-bilirrubin-INR-creatinine (ABIC) como fator prognóstico na hepatite alcoólica e sua correlação com as complicações dessa doença, com o risco de óbito e com os escores Model for End stage Liver Disease (MELD) e Função Discriminante de Maddrey. Métodos - Um total de 46 prontuários de pacientes internados por hepatite alcoólica foram avaliados de forma retrospectiva. Foi realizado levantamento de exames laboratoriais do primeiro dia de internação e 7 dias após, além de cálculo dos escores estudados. Resultados - Os índices ABIC, Maddrey e MELD apresentaram correlação positiva entre si e associaram-se a encefalopatia hepática e a ascite $(P<0,05)$. O índice ABIC, classificado de alto risco, foi fator de risco para essas complicações e para óbito. Em análise de regressão logística univariada para óbito, a razão de risco do ABIC de entrada no hospital foi de 19,27 $(P=0,012)$ e após 7 dias de 41,29 $(P=0,002)$. A sobrevida acumulada daqueles com ABIC de alto risco foi de 93,3\% em 7 dias e de apenas 26,9\% em 60 dias. Conclusão - O índice prognóstico ABIC é fator de predição para complicações como ascite e encefalopatia hepática, assim como para risco de óbito, sendo ferramenta útil na prática clínica.

DESCRITORES - Hepatite alcoólica. Índice de gravidade de doença. Bilirrubina. Creatinina. Mortalidade.

\section{REFERENCES}

1. Akriviadis E, Bolta R, Briggs W, Han S, Reynolds T, Shakil O. Pentoxifylline improves short-term survival in severe acute alcoholic hepatitis: a double-blind, placebocontrolled trial. Gastroenterology. 2000;19(6):1637-48.

2. Bruguera M, Bordas JM, Ródes J. Asymptomatic liver disease in alcoholics. Arch Pathol Lab Med. 1977;101(12):644-7.

3. Carithers RL Jr, Herlong HF, Diehl AM, Shaw EW, Combes B, Fallon HJ, Maddrey WC. Methylprednisolone therapy in patients with severe alcoholic hepatitis. A randomized multicenter trial. Ann Intern Med 1989; 110(9):685-90.

4. Chayanupatkul M, Liangpunsakul S. Alcoholic hepatits: a comprehensive review of pathogenesis and treatment. World J Gastroenterol. 2014;20(20):6279-86.

5. Dominguez M, Rincón D, Abraldes JG, Miquel R, Colmenero J, Bellot P, et al. A new scoring for prognostic stratification of patients with alcoholic hepatitis. Am J Gastroenterol. 2008;103(11):2747-56.

6. Fontes A, Figlie BN, Laranjeira R. Drinking behaviour between alcohol users: a followup study. Rev Psiq Clín. 2006;33:304-12.

7. Gao B, Bataller R. Alcoholic liver disease: pathogenesis and new therapeutic targets. Gastroenterology. 2011;141(5):1572-85.

8. Hines IN, Wheeler DM. Recent advances in alcoholic liver disease III. Role of the innate immune response in alcoholic hepatitis. Am J Physiol Gastrointest Liver Physiol. 2004;287(2):310-4.

9. Ishak KG, Zimmerman HJ, Ray MB. Alcoholic liver disease: pathologic, pathogenetic and clinical aspects. Alcohol Clin Exp Res. 1991;15(1):45-66.

10. Jepsen P, Ott P, Andersen PK, Sørensen HT, Vilstrup H. The clinical course of alcoholic liver cirrhosis: a Danish population-based cohort study. Hepatol. 2010;51(5):1675-82.
11. Kamath PS, Wiesner RH, Malinchoc M, Kremers W, Therneau TM, Kosberg $\mathrm{CL}$, et al. A model to predict survival in patients with end-stage liver disease. Hepatology. 2001;33(2):464-70

12. Lieber CS. Alcoholic liver disease: a public health issue in need of a public health approach. Semin Liver Dis. 1993;13(2):105-7.

13. Lucey DM, Mathurin P, Morgan TR. Alcoholic hepatitis. N Engl J Med. 2009;360(26):2758-69.

14. Maddrey WC, Boitnott JK, Bedine MS, Weber FL Jr, Mezey E, White RI Jr Corticosteroid therapy of alcoholic hepatitis. Gastroenterology. 1978;75(2):193-9.

15. Mathurin P, Mendenhall CL, Carithers JL Jr, Ramond MJ, Maddrey WC, Garstide $\mathrm{P}$, et al. Corticosteroids improve short-term survival in patients with severe alcoholic hepatitis $(\mathrm{AH})$ : individual data analysis of the last three randomized placebo controlled double blind trials of corticosteroids in severe AH. J of Hepatol. 2002;36(4):480-7.

16. Mathurin P, Lucey MR. Management of alcoholic hepatitis. J Hepatol. 2012;56(Suppl 1):S39-45.

17. Organização Mundial da Saúde (OMS). Global status report on alcohol. OMS, Genebra. [cited 2011]. Available from: http://www.who.int/whosis/whostat/ EN_WHS2011_Full.pdf?ua=1

18. Shah VH, Vaa BE. Alcoholic liver disease - An update. Gastroenterology Research Unit, Mayo Clinic, Rochester. US Gastroenterology \& Hepatology Review. 2009;44-8.

19. Singal AK, Shah VH. Alcoholic hepatitis: prognostic models and treatment Gastroenterol Clin North Am. 2011;40(3):611-39.

20. Sohail U, Satapathy KS. Diagnosis and management of alcoholic hepatitis. Clin Liver Dis. 2012;16(4):717-36. 